\title{
Thermal performance of steel and fibre reinforced concrete composite floor
}

\author{
Talita L. Silva ${ }^{1}$, Isabel B. Valente ${ }^{1}$, Joaquim Barros ${ }^{1}$, Maria José Roupar ${ }^{1}$, \\ Sandra M. Silva ${ }^{1}$ and Ricardo Mateus ${ }^{1}$ \\ ${ }^{1}$ University of Minho, Portugal \\ isabelv@civil.uminho.pt
}

\begin{abstract}
In general, steel and concrete composite floors tend to present a reduced functional performance (considering thermal and acoustic conditions), due to their low mass and to the high conductivity of the steel elements. By including components with high thermal insulation capacity in these structural systems, it is possible to maintain the structure lightness and not compromise the thermal performance. Within this work, the analysis is dedicated to a composite floor in which a fibre reinforced concrete (FRC) slab is associated with a concrete filled "U" type steel profile. The fibre reinforcement avoids the use of conventional reinforcement, with significant savings in term of fabrication time. Filler blocks are inserted, composed by thermal insulation material (EPS), between the "U" shaped steel profiles, which act as formwork during the casting phase and, after the concrete hardening, contributing to improve the system's thermal performance. This system was evaluated through numerical assessment. The analysis enabled to determine the thermal transmittance (U-value) and to identify the critical zones in terms of thermal insulation efficiency. The performance of the proposed solution was also compared to other flooring solutions. According to the results obtained, the proposed composite floor presents a better thermal behaviour than other more traditional flooring systems.
\end{abstract}

Keywords: steel and concrete composite floor, fibre reinforced concrete, thermal performance, numerical analysis.

\section{Introduction}

The performance of flooring solutions should be evaluated considering their mechanical and functional behaviour, in order to guarantee thermal comfort and structural safety to the users. Structural elements, as slabs, are in many cases in direct and constant contact with the outside environment, and due to their large size, they play a very important role in the heat transfer processes that occur. Despite columns and beams being smaller when compared to slabs, they also create thermal bridges. This is due to the assembly of construction elements that are composed by different materials and due to structural elements that are commonly composed by higher conductivity 
materials (concrete and steel), in comparison to the surrounding construction elements (e.g. walls).

Thermal bridges not only provide heat transfer/loss, but can also promote moisture problems. Excess moisture without adequate ventilation can lead to the appearance of bacteria and mold, compromising the users' health [1].

To characterize the thermal behaviour of a building element, it is necessary to determinate its thermal transmittance (U-value) and its thermal resistance $(\mathrm{R})$.

Thermal transmittance is inversely proportional to the construction element thermal resistance and the interior and exterior surface thermal resistances. Thermal resistance of a material or construction element can be determined through the relation between its thickness and its thermal conductivity. Thermal conductivity represents the amount of heat transfer through a layer of a thermally homogeneous material when there is a temperature difference between two flat and parallel surfaces. Interior and exterior surface thermal resistances are influenced by the air speed, the surface emissivity and the heat flux direction, which can be in horizontal or vertical direction, [2] [3]. Smaller thermal transmittance, or higher thermal resistance, leads to better thermal performance of a construction element. These properties can be quantified considering analytical and numerical approaches and must be validated by experimental testing.

Over the years, building structures have become increasingly light and slim. As a result, it has been possible to reduce the overall construction weight, and to create wider and more flexible spaces for various applications. These advantages go beyond architectonic aspects. In fact, lighter structures tend to result in more sustainable constructions. Steel and concrete composite floors are an example of a lighter and optimized structural system. However, compared to some conventional floors, the thermal performance of steel and concrete composite floors is generally less efficient, due to the reduced mass and the high conductivity of their constituent materials.

This work aims to evaluate the thermal performance of a new steel and concrete composite floor. The proposed solution, named PreSlabTec, was developed to provide the users with a good thermal performance, as well as the overall structural safety. When the thermal behaviour improves, the costs associated with heating or cooling equipment can decrease, which makes the solution more energy-efficient and, consequently, more sustainable.

PreSlabTec is a steel and concrete composite floor, where "U" shaped steel profiles are associated with fibre reinforced concrete (FRC) slab. Filler blocks in insulation material, such as expanded polystyrene (EPS), are inserted between the steel profiles, and act as formwork at the casting phase. When the concrete hardening is complete, the filler blocks contribute to improve the system's thermal performance. In this work, thermal performance is evaluated through numerical assessment. Some analyses are performed to examine the proposed solution thermal performance and to compare it with some traditionally flooring systems. 


\section{Geometry and materials definition}

The proposed system is composed by "U" shaped steel profiles, with alveolar openings, which are associated with a FRC concrete slab. The steel profiles are fabricated with steel SJ235, and a thermal conductivity value of $(\lambda) 50.0 \mathrm{~W} /\left(\mathrm{m} .{ }^{\circ} \mathrm{C}\right)$ is considered for these elements. During the casting phase, these profiles are filled with FRC and the alveolar openings allow some FRC transfer to the outside of the profile. Fibre reinforced concrete is used to avoid the use of conventional reinforcement. It was considered that FRC thermal conductivity $(\lambda)$ is equal to $2.0 \mathrm{~W} /\left(\mathrm{m} .{ }^{\circ} \mathrm{C}\right)$, which corresponds to reinforced concrete with a percentage of reinforcement that is below $1 \%$ (by volume). This property will be updated after the experimental testing. The filler blocks are compose by EPS with a thermal conductivity $(\lambda)$ of $0.036 \mathrm{~W} /\left(\mathrm{m} .{ }^{\circ} \mathrm{C}\right)$. Two transversal tubular joists cross the alveolar openings in the " $U$ " steel profile in the ends of the slab. These cross-section profiles have the same thermal conductivity as the "U" profiles. The geometry of the PreSlabTec is shown in Fig. 1.

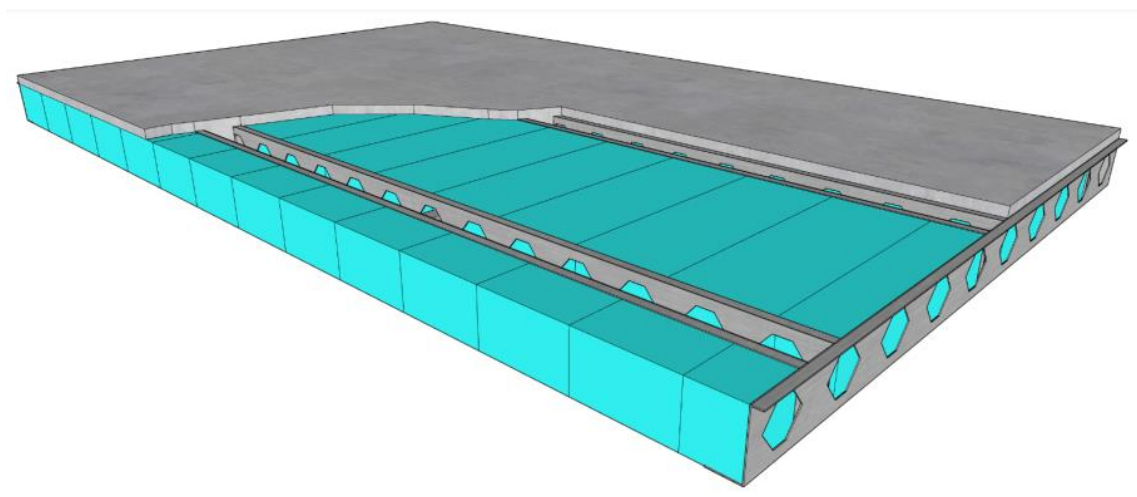

Fig. 1. Proposed steel and concrete composited floor: (a) 3D view.

\section{$3 \quad$ Numerical Assessment}

The thermal study was carried out considering 2D numerical modelling, with the aid of Therm 7 software [4], which is based on the finite element method (FEM).

The performance of all construction elements must be in accordance with the requirements of the legislation of its implementation place. The Portuguese legislation imposes requirements for building envelopes that must be fulfilled [5], as those between outside and inside spaces. The worst possible situation is considered, i.e., the slab acts as the horizontal separation between outside and inside spaces, where there is a significant temperature difference between the PreSlabTec surfaces. 


\subsection{Models}

Four numerical models were created to evaluate the PreSlabTec cross section. The first model, MN_A, corresponds to the cross section with alveolar openings in the "U” steel profiles (see Fig. 2.a). Model MN_B corresponds to the cross section without alveolar openings in the "U" steel profile (see Fig. 2.b). The third model, MN_C, correspond to the position where a transversal tubular joist crosses the alveolar openings in the "U" steel profile (see Fig. 2.c) and model MN_D corresponds to the same cross section that was chosen for model MN_C, but in the exact position of the tubular joist wall (see Fig. 2.d).
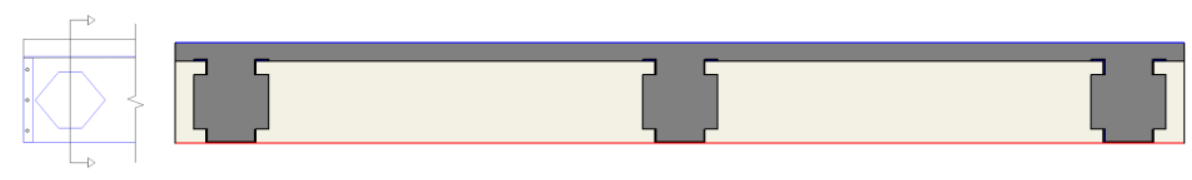

(a)
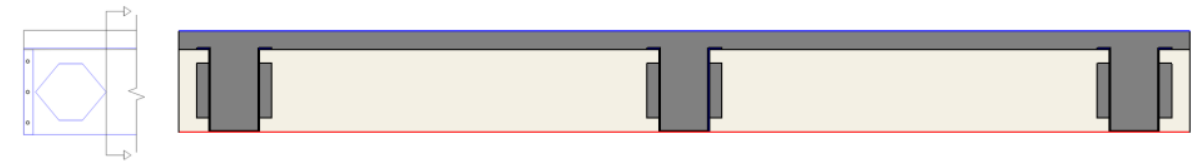

(b)
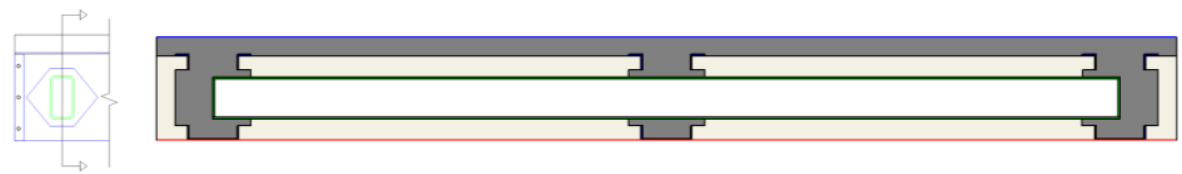

(c)
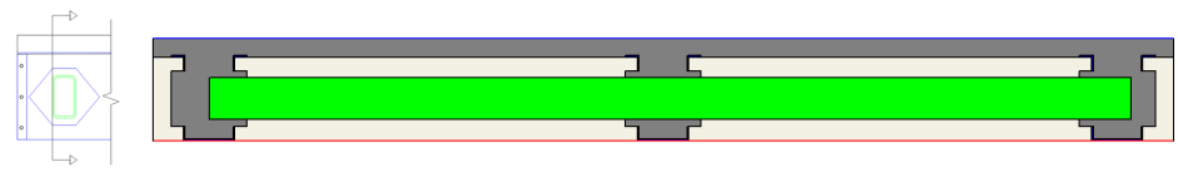

(d)

Fig. 2. Cross sections of the numerical models: (a) MN_A; (b) MN_B; (c) MN_C; (d) MN_D.

The thermal properties of the materials were described in section 2. According to [3], when the air spaces are unventilated, the air conductivity changes under the heat flux direction.

A thermal conductivity value of $0.513 \mathrm{~W} /\left(\mathrm{m} .{ }^{\circ} \mathrm{C}\right)$ was attributed to the air inside the cross section profiles, when the heat flux is ascendant and a thermal conductivity value of $0.372 \mathrm{~W} /\left(\mathrm{m} .{ }^{\circ} \mathrm{C}\right)$ was set when the heat flux is descendant. 
The models were analysed considering winter and summer seasons, in which occur the highest temperature variability between inside and outside surfaces. According to [6], when temperature inside the building is lower than $18^{\circ} \mathrm{C}$ in winter and higher than $25^{\circ} \mathrm{C}$ in summer, it is necessary to heat or cool the building. Exterior temperatures were set so that there would be a difference of at least $10^{\circ} \mathrm{C}$ between the interior and the exterior.

Adiabatic conditions were attributed to the lateral surfaces of the model, which means that there are no thermal exchanges with the building envelopes (see Fig. 3). This enables the characterization of the PreSlabTec thermal performance without considering the influence of other surrounding construction components.

The surface resistances were applied in accordance with those indicated in [3]. The boundary conditions according to the seasons of the year and heat flux direction are described in Table 1.

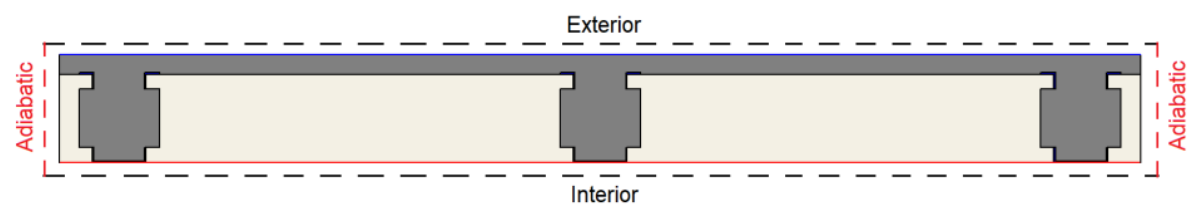

Fig. 3. Boundary conditions.

Table 1. Boundary conditions according to the heat flux direction.

\begin{tabular}{lcccc}
\hline & \multicolumn{2}{c}{ Ascending heat flux $(\uparrow)$} & \multicolumn{2}{c}{ Descending heat flux $(\downarrow)$} \\
\hline Surface & Interior & Exterior & Interior & Exterior \\
Temperature $\left({ }^{\circ} \mathrm{C}\right)$ & 18 & 8 & 25 & 35 \\
$R_{\text {surface }}\left[\left(\mathrm{m}^{2} .{ }^{\circ} \mathrm{C}\right) / \mathrm{W}\right]$ & $0.10(\uparrow)$ & $0.04(\uparrow)$ & $0.17(\downarrow)$ & $0.04(\downarrow)$ \\
\hline
\end{tabular}

\subsection{Results}

The numerical model MN_A presents the smaller thermal transmittance and the higher thermal resistance. This result was expected due to the larger area of insulating material (EPS). In contrast, model MN_D obtains the higher thermal transmittance in consequence of the larger quantity of steel, which is a conductive material. All the results obtained with the numerical models are collected in Table 2.

Although the boundary conditions are the same for all models and the thermal transmittance values obtained in the analysis are close to each other, it can be seen that in models with better thermal performance, the heat flux acting on the building element is lower (see Table 2). This results from the higher thermal resistance of the corresponding solution. 
Table 2. Numerical results.

\begin{tabular}{|c|c|c|c|c|}
\hline Model & Heat flux direction & $\begin{array}{c}U \\
{\left[\mathrm{~W} /\left(\mathrm{m}^{2} \cdot{ }^{\circ} \mathrm{C}\right)\right]}\end{array}$ & $\begin{array}{c}R \\
\left.\left[\mathrm{~m}^{2} .{ }^{\circ} \mathrm{C}\right) / \mathrm{W}\right]\end{array}$ & $\begin{array}{l}\text { Heat flux } \\
\left(\mathrm{W} / \mathrm{m}^{2}\right)\end{array}$ \\
\hline \multirow{2}{*}{ MN_A } & $\uparrow$ & 1.01 & 0.99 & 10.35 \\
\hline & $\downarrow$ & 0.82 & 1.23 & 8.16 \\
\hline \multirow{2}{*}{ MN_B } & $\uparrow$ & 1.16 & 0.87 & 11.79 \\
\hline & $\downarrow$ & 0.90 & 1.11 & 8.98 \\
\hline \multirow{2}{*}{ MN_C } & $\uparrow$ & 1.12 & 0.89 & 11.43 \\
\hline & $\downarrow$ & 0.91 & 1.10 & 9.12 \\
\hline \multirow{2}{*}{ MN_D } & $\uparrow$ & 1.32 & 0.76 & 13.48 \\
\hline & $\downarrow$ & 1.07 & 0.93 & 10.71 \\
\hline
\end{tabular}

It is possible to analyse the heat flux intensity in the models through the heat flux magnitude, which is higher according to the highest conductibility of the materials. In the MN_A model there is a heat flux difference of approximately $2 \mathrm{~W} / \mathrm{m}^{2}$ between the area with EPS and the part of the cross section that is inside of the steel profile (FRC beam + "U" steel profile). However, between some areas of the steel profile and the other elements of the model there is a more significant difference, of approximately $10 \mathrm{~W} / \mathrm{m}^{2}$ (see Fig. 4).

An ascending heat flux of $10.35 \mathrm{~W} / \mathrm{m}^{2}$ was obtained in the MN_A model. In Fig. 4 it can be seen that in the majority of the model, the heat flux is approximately $7.9 \mathrm{~W} / \mathrm{m}^{2}$, which means that the area corresponding to the " $\mathrm{U}$ " steel profile has a considerable influence on the global result, although its area is significantly smaller.

The heat flux magnitude is higher in model MN_D, when the cross-section steel profile is directly next to the "U" steel profile and involved by FRC. When it is involved by EPS, the heat flux magnitude, for this area, is the same as the one obtained in MN_A model (Fig. 4).

The global thermal transmittance $\left(U_{T}\right)$ of the proposed solution can be averaged, by accounting the area of each part of the cross section, $A_{M N, n}$, and its thermal transmittance, $U_{M N, n}$ (see Eq. 1). The construction solution presents a global thermal transmittance of $1.12 \mathrm{~W} /\left(\mathrm{m}^{2} .{ }^{\circ} \mathrm{C}\right)$ for winter, ascending heat flux, and $0.89 \mathrm{~W} /\left(\mathrm{m}^{2} .{ }^{\circ} \mathrm{C}\right)$ for summer, descending heat flux.

$$
U_{T}=\left[\Sigma\left(U_{M N \_n} \times A_{M N \_n}\right)\right] / \Sigma A_{M N \_n}
$$




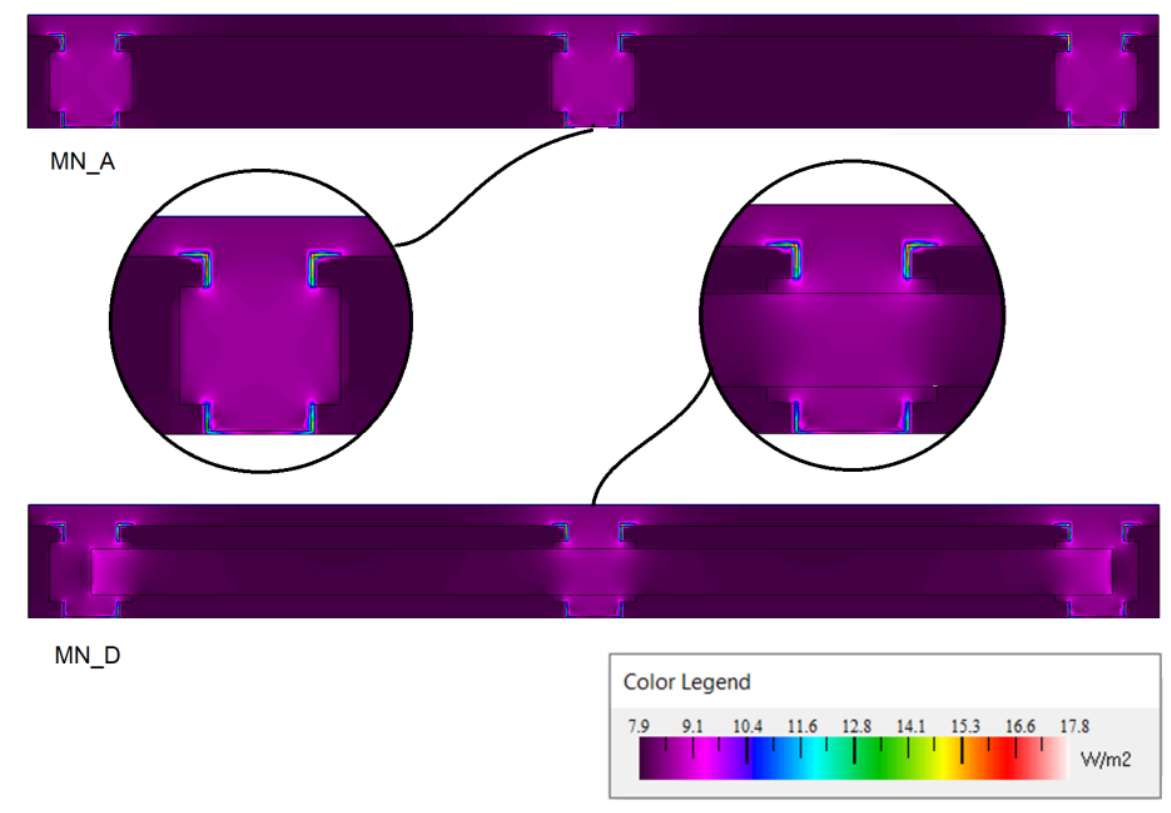

Fig. 4. Heat flux magnitude for an ascending heat flux.

\section{Comparative analysis}

For comparison purposes, it was decided to analyze other common flooring solutions. Considering this, some additional numerical models were created, corresponding to pre-selected flooring solutions, in order to assess their thermal performance.

To carry out this comparative study, three constructive solutions were selected: a reinforced concrete slab, a steel and concrete composite floor and a precast floor. These solutions were designed considering the same actions, the same span $(3.2 \mathrm{~m})$ and the same cross-section width $(2.21 \mathrm{~m})$. The cross sections geometries are described in Fig. 5.

A thermal conductivity value of $2.5 \mathrm{~W} /\left(\mathrm{m} .{ }^{\circ} \mathrm{C}\right)$ was attributed to reinforced concrete. For the steel and concrete composite floor, the value of thermal conductivity of concrete was considered equal to $2.0 \mathrm{~W} /\left(\mathrm{m} .{ }^{\circ} \mathrm{C}\right.$ ) (less reinforcement) and the value of $50.0 \mathrm{~W} /\left(\mathrm{m} .{ }^{\circ} \mathrm{C}\right)$ was attributed to the trapezoidal sheeting. For the precast floor, a thermal conductivity of $2.0 \mathrm{~W} /\left(\mathrm{m} .{ }^{\circ} \mathrm{C}\right)$ was attributed to concrete and the value of $0.34 \mathrm{~W} /\left(\mathrm{m} .{ }^{\circ} \mathrm{C}\right)$ was considered in the ceramic filler blocks. The boundary conditions considered in the PreSlabTec model were also applied to these models. The results on thermal transmittance obtained from the developed models are presented in Fig. 5. 


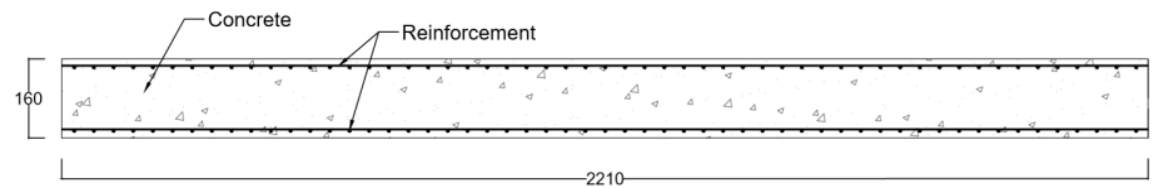

(a)

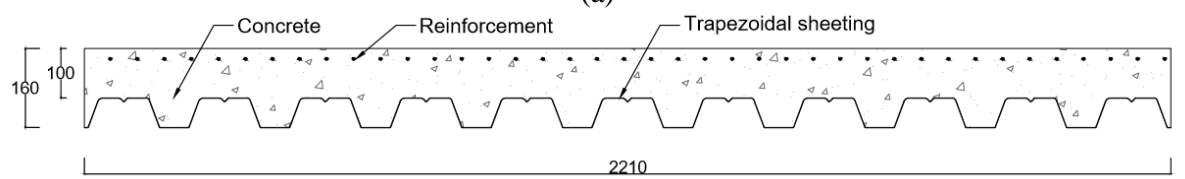

(b)

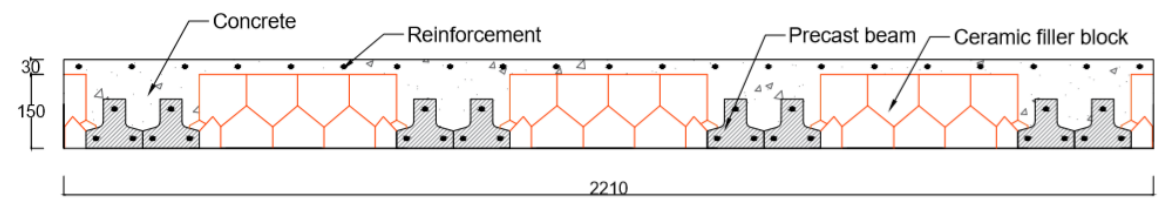

(c)

Fig. 5. Cross sections of the floor used in the comparative analysis: (a) concrete floor; (b) steel and concrete composite floor; (c) precast floor. Unit: millimeter.

The proposed solution, PreSlabTec, has a better overall performance than all the other solutions because of the large amount of insulation material that is disposed in its composition. In relation to the solutions analysed, the results were also consistent with the expected ones, as reinforced concrete floor and steel and concrete composite floor presented a higher thermal transmittance. Table 3 describes the average U-value $\left(U_{\mathrm{m}}\right)$ obtained for ascending and descending heat flux, considering all floors analyzed.

Table 3. Comparative results.

\begin{tabular}{lccc}
\hline Construction solution & $\begin{array}{c}U_{\mathrm{m}} \\
{\left[\mathrm{W} /\left(\mathrm{m}^{2} .{ }^{\circ} \mathrm{C}\right)\right]}\end{array}$ & $\begin{array}{c}R \\
{\left[\left(\mathrm{~m}^{2} .{ }^{\circ} \mathrm{C}\right) / \mathrm{W}\right]}\end{array}$ & $\begin{array}{c}\text { Heat Flux } \\
\left(\mathrm{W} / \mathrm{m}^{2}\right)\end{array}$ \\
\hline PreSlabTec & 1.00 & 1.01 & 10.16 \\
Concrete slab (Fig. 5a) & 4.28 & 0.24 & 43.24 \\
Composite slab (Fig. 5b) & 4.28 & 0.27 & 52.79 \\
Prefabricated slab (Fig. 5c) & 2.76 & 0.37 & 27.94 \\
\hline
\end{tabular}

The benefits are not only related to the thermal behaviour of the solution. According to [5] the $U_{\max }$ for horizontal building envelopes varies between $0.40 \mathrm{~W} /\left(\mathrm{m}^{2}{ }^{\circ} \mathrm{C}\right)$ and $0.30 \mathrm{~W} /\left(\mathrm{m}^{2} .{ }^{\circ} \mathrm{C}\right)$ depending on the climate zone of Portugal. As previously mentioned, these requirements are defined for building envelopes, as those that are in contact with the exterior. Considering this, all the solutions analysed would need additional insulation to fulfill the thermal transmittance demanded in [5], but in this case, the PreSlabTec solution would need a smaller amount of insulation material 
(e.g. EPS applied continuously on one of the slab surfaces, exterior or interior) to achieve the same thermal transmittance level as the other slab solutions analysed. In consequence, there is a cost reduction and a space gain that results from its lower thickness.

\section{$5 \quad$ Future study - experimental tests}

Laboratory tests will be performed to evaluate the experimental thermal performance of the proposed flooring system. The tests will be carried out according to [7] and the collected data will be used to determine its thermal transmittance $(U)$ and its thermal resistance $(R)$.

Due to the different materials used in the cross section and the geometrical variations imposed, different specimens will be created to allow the characterization of the different parts of the slab.

The experimental test should be conducted under stable thermal conditions. When the test is performed in a laboratory environment, it is possible to control the temperature that is acting on the building element to promote temperature differences between the opposite surfaces of the specimen and to avoid unstable results.

These conditions can be achieved by implementing a hot box. The hot box is composed by two chambers, metering chamber and climatic chamber, whose walls are formed by insulating material. The metering chamber contains a heating equipment and the resulting air temperature is controlled. The climatic chamber is used to control the air temperature on the opposite side of the metering chamber [8]. Masked hot box will be used since it allows to involve the whole building element. The hot box walls will be composed by $200 \mathrm{~mm}$ extruded polystyrene (XPS), $\lambda=0.038 \mathrm{~W} /\left(\mathrm{m} .{ }^{\circ} \mathrm{C}\right)$, and $50 \mathrm{~mm}$ of mineral wool, $\lambda=0.037 \mathrm{~W} /\left(\mathrm{m} .{ }^{\circ} \mathrm{C}\right.$ ) (see Fig. 6$)$.

During the experimental tests, the thermal conductivity of the fibre reinforced concrete (FRC) will also be characterised in order to calibrate and validate the numerical models.

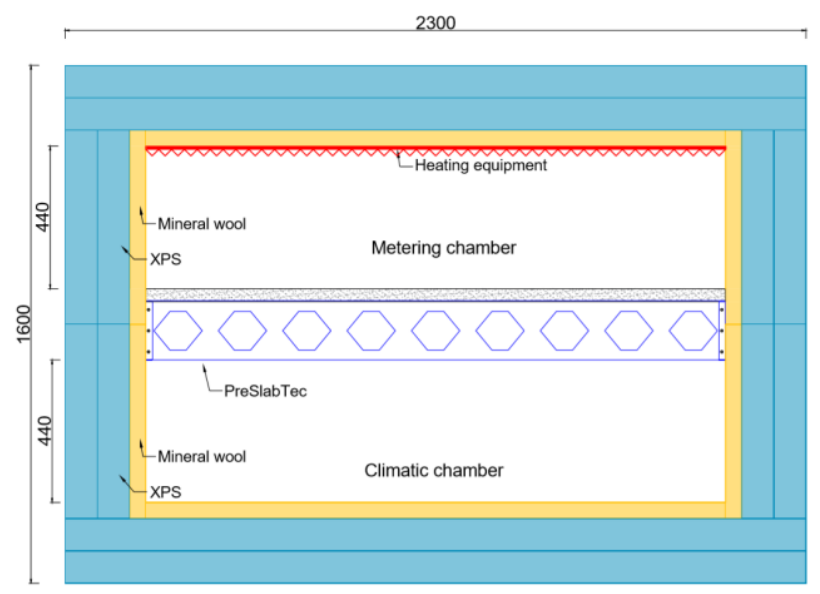

Fig. 6. Masked hot box. Unit: millimeter. 


\section{Conclusions}

This work presents a new structural flooring system designed to provide a good thermal performance in addition to its optimized structural behaviour.

The study was developed considering a numerical approach. The proposed solution presented a good performance, given the boundary conditions applied. However, there are some critical areas: the ones located next to the steel profile, where additional insulation is needed to avoid thermal bridges.

A complementary analysis was developed to evaluate the thermal behaviour of the proposed system in comparison to some traditional floors. It showed a thermal performance that is better than all the other traditional flooring systems analyzed.

In addition to this study, experimental tests will be carried out to validate the results obtained and to characterize the thermal performance of FRC.

\section{Acknowledgements}

This work was developed within the research project NORTE-01-0247-FEDER-033690-PreSlabTec, involving the companies CiviTest and Serralharia Cunha, and the research institute ISISE, at the University of Minho. The authors appreciate the contribution of the technicians of LEST - Structural Laboratory of the Civil Engineering Department, at University of Minho.

\section{References}

1. Teni, M., Krstić, H., Kosiński, P. Review and comparison of current experimental approaches for in-situ measurements of building walls thermal transmittance. Energy and Buildings (203) 109417 (2019).

2. RCCTE, "Regulamento das Características do Comportamento Térmico dos Edifícios", Decreto-Lei no 80/2006, de 4 de abril (2006).

3. LNEC. ITE50 "Térmica, Coeficientes de Transmissão Térmica de Elementos da Envolvente dos Edifícios". Lisboa (2006).

4. Finlayson, E., Mitchell, R., Dariush, A., Huizenga, C., Curcija, D: Therm 2.0: Program Description - A PC Program for Analyzing the Two-Dimentional Heat Transfer Through Building Products. - Ernest Orlando Lawrence Berkeley Nat. Laboratory. (1998).

5. Portaria n. ${ }^{3} 379-A / 2015$ de 22 de outubro. Diário da República n ${ }^{\circ}$ 207/2015, $2^{\circ}$ Suplemento, Série I. Min. do Ambiente, Ord. do Território e Energia. Lisboa.

6. REH, "Regulamento de Desempenho Energético dos Edifícios de Habitação". Decreto-Lei n. ${ }^{\circ}$ 118/2013 (2013).

7. ISO 9869-1:2014. Thermal insulation - Building elements - In-situ measurement of thermal resistance and thermal transmittance - Part 1: Heat flow meter method.

8. ASTM C1363-11. Standard Test Method for Thermal Performance of Building Materials and Envelope Assemblies by Means of a Hot Box Apparatus. 